\title{
Supporting Information for: \\ Excited State Exchange Control of Photoinduced Electron Spin Polarization in Electronic Ground States
}

\author{
Martin L. Kirk, ${ }^{1,2 *}$ David A. Shultz, ${ }^{3 *}$ Patrick Hewitt, ${ }^{3}$ and Art van der Est ${ }^{4 *}$
}

\begin{abstract}
${ }^{1}$ Department of Chemistry and Chemical Biology, The University of New Mexico, MSC03 2060, 1 University of New Mexico, Albuquerque, NM 87131-0001 USA. ${ }^{2}$ The Center for High Technology Materials, The University of New Mexico, Albuquerque, New Mexico 87106, United States, ${ }^{3}$ Department of Chemistry, North Carolina State University, Raleigh, North Carolina 27695-8204 USA. " Department of Chemistry, Brock University, St. Catharines, Ontario, CANADA L2S 3A1. e-mail: mkirk@unm.edu, shultz@ncsu.edu, avanderest@brocku.ca.
\end{abstract}

*Authors to whom correspondence should be addressed.

Compounds. Synthesis and characterization of (DMSO) ${ }_{2} \mathrm{PtCl}_{2},{ }^{2} \mathrm{H}_{2} \mathrm{CAT}-\mathrm{TMP}-\mathrm{NN},{ }^{3}$ and complex PtCAT-NN ${ }^{4}$ have been reported previously. Complex PtCAT-TMP-NN was prepared using modified conditions described for other (bpy)Pt(CAT-B-NN) complexes ${ }^{4}$ as described below. Complex Pt(DMSO) ${ }_{2}$ was prepared as described below.

PtCAT-TMP-NN. A solution of $\mathrm{H}_{2}$ CAT-TMP-NN (46 mg, $0.10 \mathrm{mmol}$ ) in $3 \mathrm{~mL}$ of DMSO was purged with argon for 30 minutes, after which bpyPtCl $2(51 \mathrm{mg}, 0.095 \mathrm{mmol})$ and $\mathrm{K}_{2} \mathrm{CO}_{3}(31 \mathrm{mg}, 0.22$ $\mathrm{mmol}$ ) were added. The reaction mixture was stirred at room temperature for $14 \mathrm{~h}$. The product was precipitated by pouring the reaction mixture into $150 \mathrm{~mL}$ of brine and then filtering. The product was collected from the filter paper by dissolving in $40 \mathrm{~mL}$ of $\mathrm{CH}_{2} \mathrm{Cl}_{2}$. The organic layer was dried with $\mathrm{MgSO}_{4}$, filtered, and concentrated under reduced pressure to afford the product (81 mg, 93\%) as a blue-purple solid. HRMS (ESI) m/z: [M+] Calculated for $\mathrm{C}_{45} \mathrm{H}_{59} \mathrm{~N}_{4} \mathrm{O}_{4} \mathrm{Pt}$ : 914.41786; Experimental: 914.41846. $\lambda_{\max }\left(\mathrm{CH}_{2} \mathrm{Cl}_{2}\right)=572 \mathrm{~nm}\left(\varepsilon_{\max }=3456 \mathrm{M}^{-1} \mathrm{~cm}^{-1}\right)$. FT-IR $\left(\mathrm{cm}^{-1}\right)$ : 2964, 2924, 2866, 1611, 1555, 1480, 1455, 1361, 1236, 967, 805, 672, 597, 536, 422. EPR (X-band: $9.847 \mathrm{GHz}): \mathrm{g}=2.0068 a_{N}=7.46 \mathrm{G}$.

1-Pt(DMSO) 2. A $10 \mathrm{~mL}$ round-bottom flask containing $\mathrm{H}_{2}$ Cat-NN (50 $\mathrm{mg}, 0.16 \mathrm{mmol}$ ), (DMSO) ${ }_{2} \mathrm{PtCl}_{2}(67 \mathrm{mg}, 0.16 \mathrm{mmol})$, and $\mathrm{K}_{2} \mathrm{CO}_{3}(47 \mathrm{mg}, 0.34 \mathrm{mmol})$ was purge-pumped three times, backfilling with nitrogen. Then, $3 \mathrm{~mL}$ of DMSO were added and the reaction mixture was stirred at $60^{\circ} \mathrm{C}$ under nitrogen for $16 \mathrm{~h}$. The product was transferred to a separatory funnel with $20 \mathrm{~mL}$ of brine and extracted with $20 \mathrm{~mL}$ of $\mathrm{CH}_{2} \mathrm{Cl}_{2}$. The organic layer was separated, dried with $\mathrm{MgSO}_{4}$, filtered, and concentrated under reduced pressure to afford the crude product which was purified by deactivated ( $1 \% \mathrm{Et}_{3} \mathrm{~N}$ in eluent) silica column chromatography and eluting with $10 \%$ acetone/Et ${ }_{2} \mathrm{O}$. The product-containing fraction were concentrated to afford the title compound (57 mg, 55\%) as a blue solid. [M+H] ${ }^{+}$Calculated for $\mathrm{C}_{21} \mathrm{H}_{35} \mathrm{~N}_{2} \mathrm{O}_{6} \mathrm{~S}_{2} \mathrm{Pt}$ : 671.1664; Experimental: 671.1655. . $\lambda_{\max }\left(\mathrm{CH}_{2} \mathrm{Cl}_{2}\right)=644 \mathrm{~nm}\left(\varepsilon_{\max }=783 \mathrm{M}^{-1} \mathrm{~cm}^{-1}\right)$. FT-IR (evaporated film; $\left.\mathrm{cm}^{-1}\right)$ : 2991, 2915, 
2853, 1558, 1455, 1402, 1377, 1344, 1283, 1244, 1136, 1019, 925, 819, 800, 688, 605, 538, 430.

EPR (300 K, X-band: $9.845 \mathrm{GHz}): \mathrm{g}=2.0070, a_{N}=7.75 \mathrm{G}$.

\section{References}

1. "Molecular Triangle of Palladium(II) and Its Anion Binding Properties," Qin, Z.; Jennings, M. C.; Puddephatt, R. J. Inorg. Chem. 2002, 41, 3967-3974.

2. "Palladium(II) and Platinum(II) Alkyl Sulfoxide Complexes - Examples of Sulfur-Bonded, Mixed SulfurBonded and Oxygen-Bonded, and Totally Oxygen-Bonded Complexes," Price, J. H.; Schramm, R. F.; Wayland, B. B.; Williamson, A. N. Inorg. Chem. 1972, 11 (6), 1280-1284.

3. "Determining the Conformational Landscape of $\sigma$ and $\pi$ Coupling Using para-Phenylene and 'AviramRatner' Bridges," Stasiw, D. E.; Zhang, J.; Wang, G.; Dangi, R.; Stein, B. W.; Shultz, D. A.; Kirk, M. L.; Wojtas, L.; Sommer, R. D. J. Am. Chem. Soc. 2015, 137, 9222-9225.

4. "Wave Function Control of Charge-Separated Excited-State Lifetimes," Tichnell, C. R.; Daley, D. R.; Stein, B. W.; Shultz, D. A.; Kirk, M. L.; Danilov, E. O. J. Am. Chem. Soc. 2019 141, 3986-3992; "Electronic and Exchange Coupling in a Cross-Conjugated D-B-A Biradical: Mechanistic Implications for Quantum Interference Effects," Kirk, M. L.; Shultz, D. A.; Stasiw, D. E.; Habel-Rodriguez, D.; Stein, B.; Boyle, P.D. J. Am. Chem. Soc. 2013, 135, 14713-14725.

EPR Measurements. Samples for steady state and transient EPR measurements were prepared by dissolving solid metal complexes in 2-methyl-THF to a concentration of $\sim 0.5 \mathrm{mM}$. The samples were placed in $4 \mathrm{~mm}$ O.D. quartz EPR tubes and degassed by repeated freeze-pump-thaw cycles. The frozen, degassed samples were then transferred without thawing from liquid nitrogen to the spectrometer cryostat, which was at $20 \mathrm{~K}$. The steady state spectra were collected using field modulation detection with a modulation amplitude of $0.1 \mathrm{mT}$ and a microwave power of $6.3 \mathrm{~mW}$. TREPR time/field dataset were collected with direct detection at the microwave power as for the steady state experiments. The samples were irradiated at $532 \mathrm{~nm}$ using $10 \mathrm{~ns}$ laser flashes from a frequency doubled NdYAG laser. The modified Bruker EPR 200D-SRC X-band spectrometer used for the EPR experiments has been described in detail elsewhere. ${ }^{5}$

\section{References}

5. "Electron transfer in cyanobacterial Photosystem I-I. Physiological and spectroscopic characterization of sitedirected mutants in a putative electron transfer pathway from A0 through A1 to F-x," Xu, W.; Chitnis, P.; Valieva, A.; van der Est, A.; Pushkar, Y. N.; Krzystyniak, M.; Teutloff, C.; Zech, S. G.; Bittl, R.; Stehlik, D.; Zybailov, B.; Shen, G. Z.; Goldbeck, J. H.. J. Biol. Chem. 2003, 278, 27864-27875. 